OPEN ACCESS

Edited by:

Zhao-Dong $X u$,

Southeast University, China

Reviewed by:

Yong Li,

University of Alberta, Canada

Wensheng Lu,

Tongji University, China

*Correspondence:

Jianping Han

jphan1970@163.com

Specialty section:

This article was submitted to

Structural Materials,

a section of the journal

Frontiers in Materials

Received: 28 February 2019 Accepted: 24 April 2019 Published: 10 May 2019

Citation: Liu W and Han J (2019) Experimental Investigation on Compressive Toughness of the PVA-Steel Hybrid

Fiber Reinforced Cementitious Composites. Front. Mater. 6:108. doi: 10.3389/fmats.2019.00108

\section{Experimental Investigation on Compressive Toughness of the PVA-Steel Hybrid Fiber Reinforced Cementitious Composites}

\author{
Wenlin Liu and Jianping Han* \\ Key Laboratory of Disaster Prevention and Mitigation in Civil Engineering of Gansu Province, Lanzhou University of \\ Technology, Lanzhou, China
}

In order to achieve the whole process control of crack formation of engineered cementitious composites (ECC) under loading and improve the mechanical properties of ECC, steel fibers are mixed into traditional ECC to get polyvinyl alcohol (PVA)-steel hybrid fiber reinforced cementitious composites (HyFRCC). And the key parameters to affect the HyFRCC performance are PVA fiber content, steel fiber content, and aspect ratio of steel fiber. In order to investigate the mechanical properties of PVA-steel HyFRCC such as the compressive toughness, 15 PVA-steel HyFRCC specimens with different volume fraction of steel fiber and PVA fiber, together with 1 non-fibrous cementitious composites specimen and 3 ECC specimens with PVA fibers only for comparison were designed and uniaxial compression tests were conducted. Furthermore, the effect of fiber content, fiber type and fiber geometrical characteristic on the compressive toughness of HyFRCC were analyzed. The results show that PVA fiber content, steel fiber content and aspect ratio of steel fiber have little impact on the uniaxial compressive strength of the PVA-steel HyFRCC, while the peak strain, compressive toughness and the post-peak ductility of PVA-steel HyFRCC are improved significantly due to fiber hybridization. The formation of large scale cracks of ECC specimens after post-peak loading is restrained effectively with the addition of steel fiber. The mixture of PVA and steel fiber has a remarkable effect on the improvement of ECC compression toughness and crack control. It indicates that the energy dissipation and damage control capacity of the structural component with PVA-steel HyFRCC under seismic loading will be enhanced.

Keywords: hybrid fiber, PVA fiber, steel fiber, engineered cementitious composite, compressive toughness, seismic performance improvement

\section{INTRODUCTION}

The brittleness of ordinary concrete is an important factor that seriously restricts the workability and durability of concrete structures under complex loading conditions. Engineered cementitious composites (ECC) is a new civil engineering material proposed by Li with high crack resistance and damage resistance (Li and Leung, 1992; Li, 1993; Wang and Li, 2006). ECC material shows multiple cracking and strain-hardening behavior under tensile loading. The ultimate tensile strain of ECC can reach several hundred times that of ordinary concrete, which effectively overcomes the 
brittleness and improves the tensile ductility of ordinary concrete. The excellent mechanical and durability properties make ECC potential for resilient, durable, and sustainable civil infrastructures. A lot of research works on the properties of ECC material have been done which results in improving the traditional ECC material to get high performance ECCs such as the ultra-high ductile ECC that matches strength (Wang et al., 2015) and low drying shrinkage ECC (LSECC) (Zhang et al., 2009). At present, ECC has been widely used in many civil engineering fields such as bridge deck, pavement expansion joints and structural repair (Qian et al., 2009; Fan et al., 2017; Zhou et al., 2018).

It is necessary to fully understand the mechanical properties of the material when designing the structure and simulating the response of the structure and component. Most researches on the mechanical properties of ECC material mainly focus on the uniaxial tensile properties and the bending resistance. However, the basic uniaxial compression properties of ECC have not been widely concerned. Xu et al. (2009) and Cai and $\mathrm{Xu}$ (2011) investigated the uniaxial compression behavior of ECC materials using prismatic specimens and proposed the uniaxial compression constitutive model of ECC further. Deng et al. (2015) investigated the influence of different fiber content, water-binder ratio and fly ash content on ECC compressive toughness and obtained the relationship between fiber content and compressive toughness index of ECC. Zhou et al. (2015) tested the uniaxial compression of ECC with different strength and found that the compressive toughness of ECC decreases significantly with the increase of strength. Due to the higher pullout rate and the smaller dimension of PVA fiber, it is difficult to obtain full process control of crack formation simply via PVA fiber only. It was found that the mechanical properties of traditional ECC materials can be improved with the addition of high-modulus fibers such as steel fiber (Kawamata et al., 2003; Lawler et al., 2005; Maalej et al., 2005; Zhang et al., 2007). Soe et al. (2013) investigated the tensile characteristics and the rate dependence of the hybrid fiber reinforced ECC material with $1.75 \%$ PVA and $0.58 \%$ steel fiber, and it was found that the hybrid fiber reinforced ECC material exhibits improved strength, strain capability and impact resistance. Ali et al. (2017) investigated the impact resistance of an innovative hybrid fiber reinforced ECC incorporating short randomly dispersed shape memory alloy and PVA fibers using a drop weight impact test, and their results indicate that SMA fiber significantly enhances the tensile and impact performance of the ECC. The addition of steel fiber to the traditional ECC material is expected to achieve full crack control and high compressive toughness of ECC material.

In order to investigate the mechanical properties of PVAsteel HyFRCC such as the compressive toughness and the key parameters to affect HyFRCC performance, 15 PVA-steel HyFRCC specimens with different volume fraction of steel fiber and PVA fiber, together with 1 non-fibrous cementitious composites specimen and 3 ECC specimens with PVA fibers only were designed and uniaxial compression tests were conducted. And the effect of PVA fiber content, steel fiber content and aspect ratio of steel fiber on the mechanical properties of HyFRCC such as axial compressive strength, peak strain and compressive toughness were analyzed further.

\section{EXPERIMENTAL PROGRAM}

\section{Material Composition and Mix Ratio}

Ordinary Portland cement P.O 42.5, class II fly ash and standard sand for cement strength test were used to design the materials in this study. According to the recommendations for design and construction of ECC and the previous research results, the mix ratio of HyFRCC was designed. All of these mixtures that investigated in this study had the same cement, fly ash, sand, and water. The only difference was the type of used fibers and their combination. The quantity of each constituent of the material except fibers is given in Table $\mathbf{1}$.

Three types of steel fibers with different aspect ratios shown in Table 2 were used. The PVA fibers used in this study is made by Kuraray and titled as KURALON KII RECS15. The properties of PVA fiber were shown in Table 3.

\section{Specimens Design and Test Setup}

Three parameters such as PVA fiber content, steel fiber content and aspect ratio of steel fiber were considered in this study. As shown in Table 4, 15 PVA-steel HyFRCC (A5A19) with different volume fraction of steel fiber and PVA fiber, together with 1 non-fibrous cementitious composites (A1) and 3 ECC with PVA fiber only for comparison were investigated.

For each composite, three test cubes with the dimension of $150 \times 150 \times 150 \mathrm{~mm}$ and three test prisms with the dimension of $150 \times 150 \times 300 \mathrm{~mm}$ were cast in steel molds and compacted by vibration table. All specimens were demoulded $24 \mathrm{~h}$ after casting

TABLE 1 | Mixture design $\left(\mathrm{kg} / \mathrm{m}^{3}\right)$.

\begin{tabular}{lccc}
\hline Cement & Fly ash & Sand & Water \\
\hline 530 & 753 & 467 & 404.5 \\
\hline
\end{tabular}

TABLE 2 | The mechanical and geometrical properties of steel fiber.

\begin{tabular}{lccccl}
\hline Fiber & Length (mm) & $\begin{array}{c}\text { Diameter } \\
(\mathbf{m m})\end{array}$ & $\begin{array}{c}\text { Tensile } \\
\text { strength } \\
(\mathbf{M P a})\end{array}$ & $\begin{array}{c}\text { Density } \\
\left(\mathbf{g} / \mathbf{c m}^{\mathbf{3}} \mathbf{)}\right.\end{array}$ & Type \\
\hline $\mathrm{S}_{\mathrm{a}}$ & 24 & 0.6 & $\geq 600$ & 7.8 & Crimped steel \\
$\mathrm{S}_{\mathrm{b}}$ & 36 & & & & \\
$\mathrm{~S}_{\mathrm{c}}$ & 48 & & & & \\
\hline
\end{tabular}

TABLE 3 | The mechanical and geometrical properties of PVA fiber.

\begin{tabular}{lccccc}
\hline $\begin{array}{l}\text { Length } \\
(\mathbf{m m})\end{array}$ & $\begin{array}{c}\text { Diameter } \\
(\boldsymbol{\mu m})\end{array}$ & $\begin{array}{c}\text { Tensile } \\
\text { strength } \\
(\mathbf{M P a})\end{array}$ & $\begin{array}{c}\text { Elongation } \\
(\%)\end{array}$ & $\begin{array}{c}\text { Modulus } \\
(\mathrm{GPa})\end{array}$ & $\begin{array}{c}\text { Density } \\
\left(\mathbf{g} / \mathbf{c m}^{3}\right)\end{array}$ \\
\hline 12 & 40 & 1,600 & 6 & 40 & 1.3
\end{tabular}


and stored in a standard curing room with $20 \pm 2{ }^{\circ} \mathrm{C}$ and $95 \% \mathrm{RH}$ for additional 27 days.

\section{Loading Device and Control Method}

The compression tests were conducted by an electro-hydraulic servo compression machine with a load capacity of 300t. As shown in Figure 1A, cubes were tested to obtain the 28-day compressive strength and the tests were performed under a constant rate of $0.5 \mathrm{MPa} / \mathrm{s}$. As shown in Figure 1B, prisms were tested to evaluate the full compressive loading-displacement response of the composites. A displacement control with 0.3 $\mathrm{mm} / \mathrm{min}$ loading velocity was applied in the axial direction until ultimate failure occurred. Two grating displacement sensors were used to measure the vertical deformation in the gauge range of the specimens.

\section{Test Phenomena}

The axial compression resistance of non-fibrous cementitious composites is similar to that of ordinary concrete. After the peak load, a vertical main crack is formed through the prisms. The matrix on both side of the crack is obviously dislocated and the prisms lose the bearing capacity. The failure mode of the non-fibrous matrix is shown in Figure 2A.

There is a significant difference between the fiber reinforced cementitious composites and non-fibrous cementitious composites in the process of compression. The development of cracks is still in control after the peak load due to the addition of fibers and new cracks develop continuously. The residual loading capacity of the specimens is still maintained when they come to failure.

There is obvious difference between the ECC and HyFRCC prismatic specimens in the process of compression. At the initial stage of loading, the lateral deformation of the ECC and HyFRCC prismatic specimens is small, the specimens are in the linear elastic stage. When the vertical loads come up to $40 \sim 60 \%$ of the peak load, the lateral deformation of the prismatic specimens is obviously increased. A number of fine cracks appear on the surface of the prisms. Due to the bridging of PVA fibers at the micro-crack, the generation and development of the microcrack can well be inhibited and the specimens is still in the elastic stage approximately. When the vertical loads come up to more than $80 \%$ of the peak load, the lateral deformation of the prismatic specimens increases rapidly. The main vertical crack is formed and $45^{\circ}$ oblique cracks are generated between the vertical cracks and the fizz sound that is produced by pulling out and snapping of PVA fibers can be clearly heard with the increase of the crack width. After peak load, the main vertical crack of the ECC prismatic specimens becomes wider suddenly and the

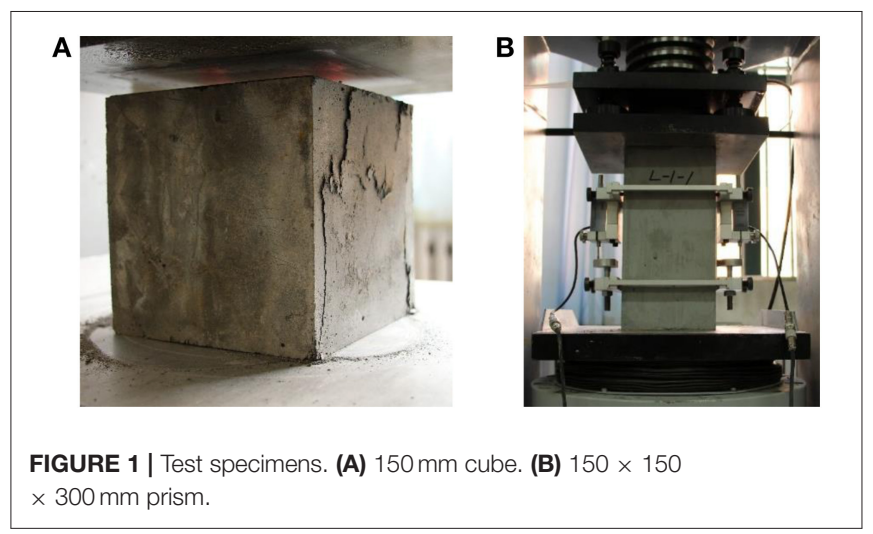

TABLE 4 | Test group and test results.

Specimen number PVA fiber (\% vol.) Steel fiber (\% vol.) Aspect ratio of steel fiber Peak loading (kN) Peak deformation (mm) Peak strain ( $\mu \mathrm{m} / \mathrm{mm})$

\begin{tabular}{|c|c|c|c|c|c|c|}
\hline $\mathrm{A} 1$ & - & - & - & 1033.5 & 0.363 & 2,416 \\
\hline A2 & 0.5 & - & - & 918.00 & 0.565 & 3,764 \\
\hline A3 & 1.0 & - & - & 961.50 & 0.658 & 4,384 \\
\hline A5 & 1.0 & 0.5 & 40 & 918.75 & 0.773 & 5,153 \\
\hline A6 & 1.0 & 1.0 & 40 & 923.25 & 0.788 & 5,253 \\
\hline A7 & 1.0 & 1.5 & 40 & 954.00 & 0.802 & 5,348 \\
\hline A10 & 1.0 & 1.5 & 80 & 951.00 & 0.811 & 5,404 \\
\hline A11 & 0.5 & 0.5 & 60 & 862.50 & 0.741 & 4,940 \\
\hline A12 & 0.5 & 1.0 & 60 & 885.00 & 0.777 & 5,180 \\
\hline A13 & 0.5 & 1.5 & 60 & 895.50 & 0.794 & 5,291 \\
\hline A14 & 1.0 & 0.5 & 60 & 918.75 & 0.845 & 5,633 \\
\hline A18 & 1.5 & 1.0 & 60 & 964.50 & 0.950 & 6,335 \\
\hline A19 & 1.5 & 1.5 & 60 & 979.88 & 0.968 & 6,450 \\
\hline
\end{tabular}


bearing capacity of the prisms drops sharply. Nevertheless, the existence of PVA fibers makes it still have some residual bearing capacity. For HyFRCC specimens, due to the presence of steel fiber, the main vertical crack width does not change abruptly after the peak load, and the development of the main crack can be controlled effectively during the decline of bearing capacity. In the meantime, new cracks are still formed in the prisms. Furthermore, the residual bearing capacity of the HyFRCC specimens is higher than that of the ECC specimens significantly. It indicates that HyFRCC is superior to the mono fiber reinforced cementitious composites in compressive toughness and crack control. The failure modes of the ECC specimens and the HyFRCC specimens are shown in Figures 2B,C.

\section{TEST RESULTS AND ANALYSIS}

\section{Load-Deformation Curves}

According to the test results, the axial compression loaddeformation curves of the non-fibrous, the ECC and the HyFRCC prisms are shown in Figure 3. The peak load and peak deformation of each prism are shown in Table 4.

As shown in Figure 3 and Table 4, the axial compressive strength of the fiber reinforced cementitious composites is smaller than that of the non-fibrous cementitious composites. The axial compressive strength of the ECC is about $10 \%$ lower than that of the non-fibrous cementitious composites, which is similar to the test results by Zhou et al. (2015) and
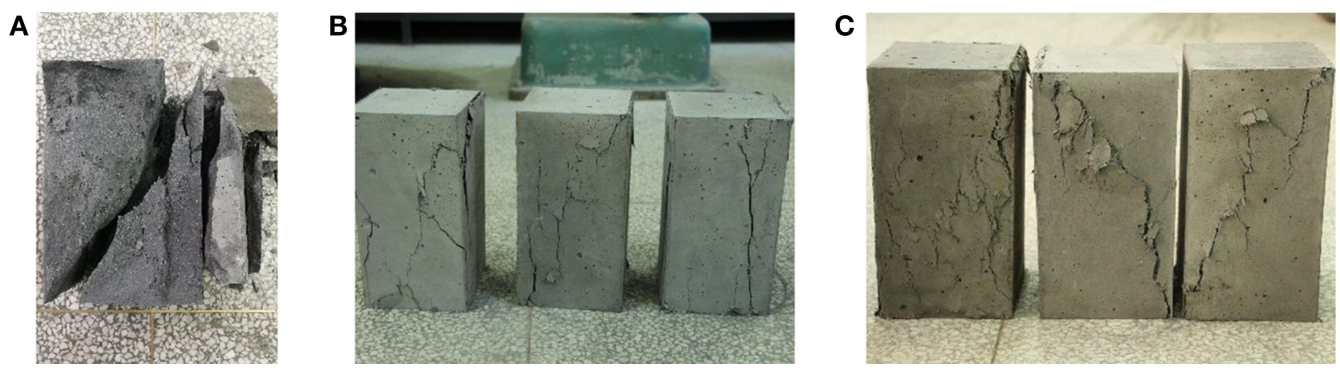

FIGURE 2 | Failure modes of tested prisms. (A) Non-fibrous. (B) ECC. (C) HyFRCC.
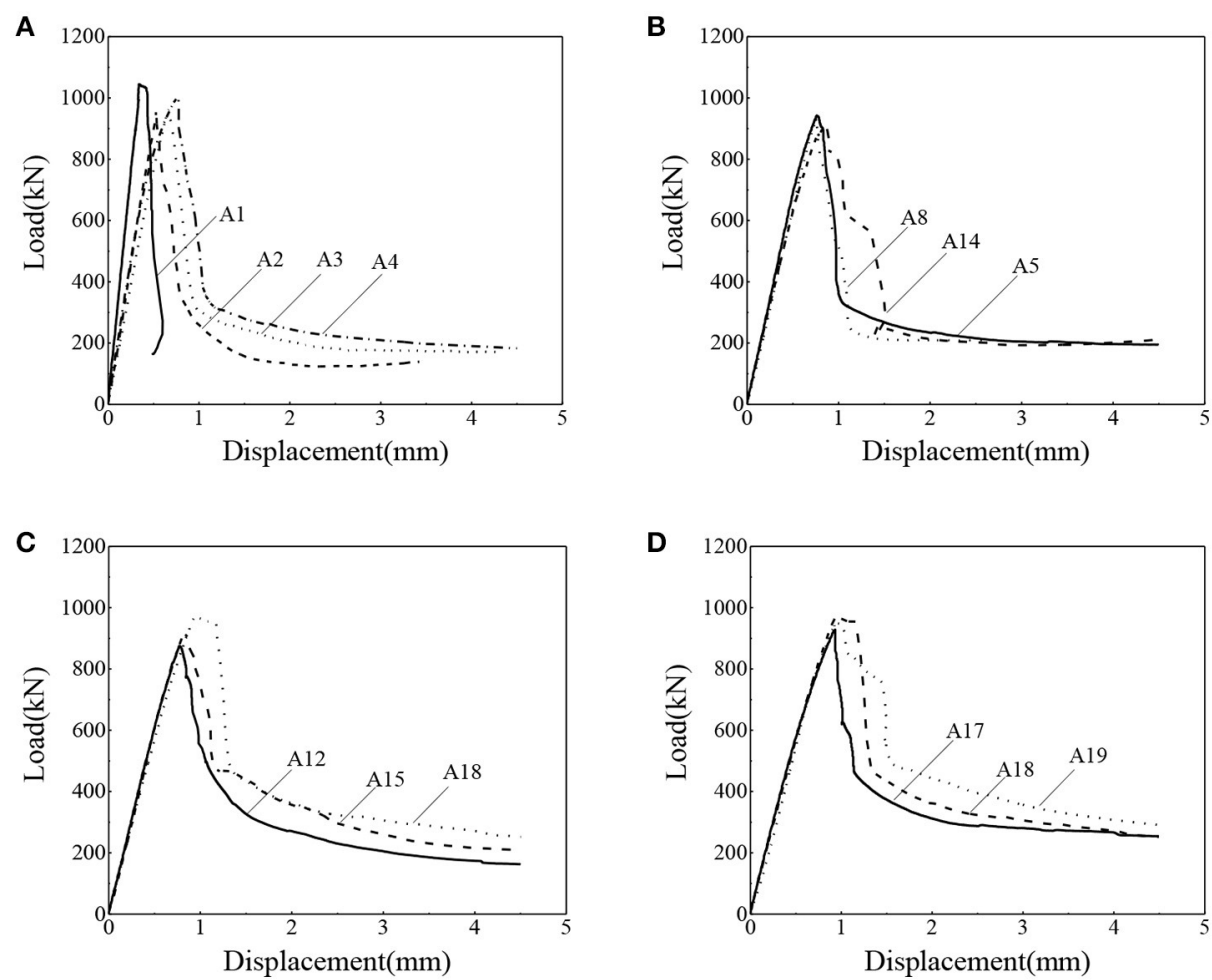

FIGURE 3 | The uniaxial compressive load-deformation curves of test specimens. (A) Non-fibrous and ECC. (B) Hybrid mixtures with variable aspect ratios of steel fiber. (C) Hybrid mixtures with variable volume fraction of PVA fiber. (D) Hybrid mixtures with variable volume fraction of steel fiber. 
Wang et al. (2018). The results of the preliminary mix ratio test show that the axial compressive strength of the mono steel fiber specimen is about $5 \%$ lower than that of the non-fibrous cementitious composites. The addition of fibers introduces more defects in the matrix during the mixing, which leads to the reduction of the axial compressive strength of the specimen. Since the size of the steel fiber is much larger than the PVA fiber, the defect introduced by steel fibers is less than that introduced by PVA fibers with the same volume fraction. Thus, the strength reduction caused by steel fibers is less than that caused by PVA fibers. The addition of PVA fiber and steel fiber mainly bridges the matrix at the crack and improve the ductility of the material.

It can be seen from Figure 3 and Table 4 that the peak strain of each mixture is in the range from 3,500 to $6,500 \mu \mathrm{m} / \mathrm{mm}$, which is much higher than the peak strain of the non-fibrous specimen, $2,416 \mu \mathrm{m} / \mathrm{mm}$. The peak strain of ECC and HyFRCC is increased by $55 \sim 105 \%$ and $104 \sim 167 \%$, respectively, which indicates that the addition of steel fiber has a significant effect on improving the deformation capability of the material before peak load, and the peak strain of the prismatic specimens increases gradually with the increase of steel fiber content. The peak strain of the HyFRCC specimens increases first and then decreases with the increase of the aspect ratio of steel fiber while the PVA fiber content and steel fiber content remain constant. When the aspect ratio of steel fiber is 60 , the peak strain is maximum.

\section{Compressive Strength}

For the tested specimens in this paper, the axial compressive strength of ECC and HyFRCC increases with the increase of fiber content. In order to accurately quantify the influence of fiber size and fiber content to the axial compressive strength of the material, the concept of fiber characteristic value was introduced as:

$$
\left\{\begin{array}{cc}
\lambda_{\mathrm{pf}}=\rho_{\mathrm{pf}} l_{\mathrm{pf}} / d_{\mathrm{pf}} & 0.5 \% \leq \rho_{\mathrm{pf}} \leq 1.5 \% \\
\lambda_{\mathrm{sf}}=\rho_{\mathrm{sf}} l_{\mathrm{sf}} / d_{\mathrm{sf}} & 0.5 \% \leq \rho_{\mathrm{sf}} \leq 1.5 \%
\end{array}\right.
$$

where $\rho_{\mathrm{pf}}$ and $\rho_{\text {sf }}$ are the content of PVA fiber and steel fiber of the matrix, respectively, $l_{\mathrm{sf}} / d_{\mathrm{sf}}$ and $l_{\mathrm{pf}} / d_{\mathrm{pf}}$ are the aspect ratio of steel fiber and PVA fiber, respectively.

As shown in Figure 4, the relationship between the fiber characteristic value and the axial compressive of the material based on the test results is obtained as:

$$
f_{\mathrm{c}}^{\prime}=f_{\mathrm{c}}\left(1-0.1628 \lambda_{\mathrm{pf}}^{-1}-0.0128 \lambda_{\mathrm{sf}}^{-1}\right)
$$

where $f_{\mathrm{c}}$ and $f_{\mathrm{c}}^{\prime}$ are the axial compressive strength of non-fibrous and HyFRCC matrix, respectively. When the content of PVA fiber and steel fiber are equal to zero, $f_{\mathrm{c}}^{\prime}$ is equal to $f_{\mathrm{c}}$.

\section{Compressive Toughness}

The compressive toughness index is important for quantitative analysis of energy dissipating ability of materials. At present, the commonly used compressive toughness analysis methods include energy method, strength method, energy ratio method and feature point method (Liu et al., 2005). The equivalent compressive toughness method proposed by Deng et al. (2015) was used to analyze and evaluate the compressive toughness of each specimen in this paper, as shown in Figure 5.

The compressive toughness index is calculated using the following equation:

$$
W_{\mathrm{c}}^{u}=\frac{\Omega_{u}}{A l}
$$

where $W_{c}^{u}$ represents the equivalent compressive toughness index, $\Omega_{u}$ is the area under the load-deformation curve at vertical deformation of $\Delta_{u}, \Delta_{u}$ is the vertical deformation corresponding to the axial load while the axial load is reduced to $u$ times peak
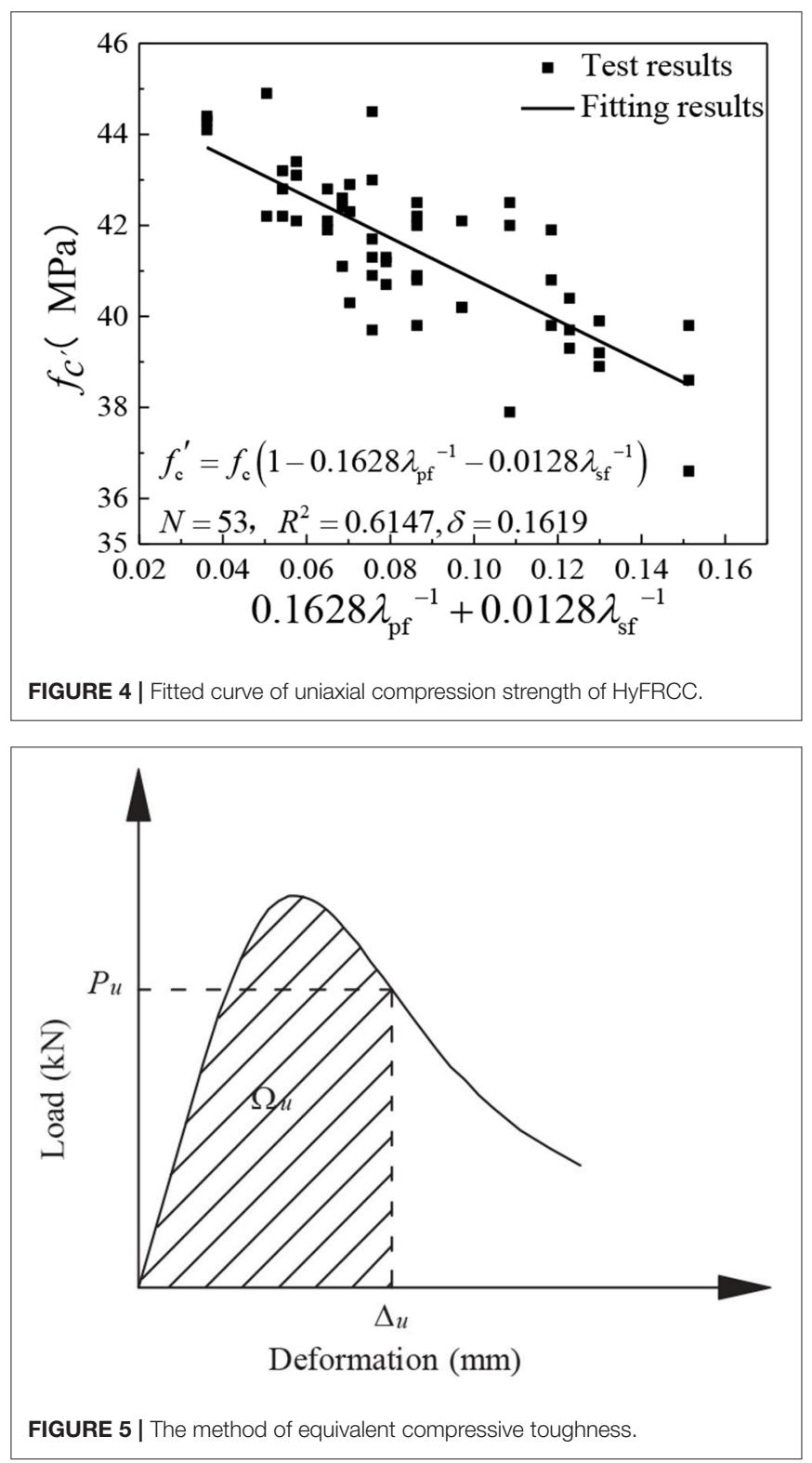
load, $A$ is the uniaxial compression area of the test specimen, $l$ is the axial height of the test specimen.

As shown in Table 5, the equivalent compressive toughness index of each specimen when $u$ is $1.00,0.85$ and 0.3 was calculated based on the test results, respectively. $W_{\mathrm{c}}^{1.00}$ corresponds to the compressive toughness when the specimen reaches to the ultimate load, which can be used for the analysis of bearing capacity of structures in the normal service condition. $W_{\mathrm{c}}^{0.85}$ corresponds to the compressive toughness when the load of the specimen declines to 0.85 times ultimate load, which can be used to evaluate the ductility and energy dissipation of structures. $W_{\mathrm{c}}^{0.30}$ corresponds to the compressive toughness when the load of the specimen declines to 0.30 times ultimate load, which can be used for collapse resistance analysis of structures.

The matrix material is typically brittle, and its compressive toughness index is significantly smaller than that of fibrous material. The fibers distributed in cementitious composites can bridge the matrix on both side of cracks, limit the generation and development of internal cracks in the matrix, and improve the vertical deformation capacity and compressive toughness of the specimen. Comparing with the non-fibrous cementitious composites specimen, $W_{\mathrm{c}}^{1.00}, W_{\mathrm{c}}^{0.85}$, and $W_{\mathrm{c}}^{0.30}$ values of fibrous specimens increase by $82.87,69.16$, and $135.32 \%$ on average, respectively.

The PVA fiber and steel fiber in fiber reinforced cementitious composites can effectively inhibit the formation and development of cracks. Among them, the PVA fiber with smaller scale mainly inhibits the formation and development of fine cracks, while the steel fiber with larger scale mainly controls the development of wider cracks. As shown in Table 5, due to the special pullout mechanism of PVA fiber, the compressive toughness of ECC that with PVA fiber only is not much higher than that of the non-fibrous cementitious composites specimen. $W_{\mathrm{c}}^{1.00}, W_{\mathrm{c}}^{0.85}$, and $W_{\mathrm{c}}^{0.30}$ values of ECC specimens increase by $54.71,24.92$, and $58.90 \%$ on average, respectively. With the addition of steel fiber with larger scale, the uniaxial compressive toughness of HyFRCC is obviously improved, the $W_{\mathrm{c}}^{1.00}, W_{\mathrm{c}}^{0.85}$, and $W_{c}^{0.30}$ values of HyFRCC specimens increase by 88.50, 76.46, and $150.61 \%$ on average, respectively.

\section{The Influence of Various Parameters on the Toughness Index}

The relationship between the compressive toughness index of the material and the PVA fiber content, steel fiber content and aspect ratio of steel fiber are shown in Figure 6.

The influence of various parameters on the compressive toughness index are summarized as follows:

As shown in Figures $\mathbf{6 B}, \mathbf{E}, \mathbf{H}$, the compressive toughness index values of the fiber reinforced cementitious composites specimens increases with the increase of volume fraction of PVA fiber. Due to the special pullout mechanism of PVA fiber, the compressive toughness of ECC specimens is significantly lower than that of HyFRCC specimens, as shown in Figure $\mathbf{6 H}$.

Steel fiber can effectively inhibit the development of wide cracks. However, the addition of steel fiber will inevitably introduce defects into the matrix. The combination of the two causes weakens the improvement of the compressive toughness which was enhanced by steel fibers. As shown in Figures 6D,G, the compressive toughness index values of the HyFRCC specimens increase first and then decrease with the increase of the steel fiber content while the PVA

TABLE 5 | Calculated results of equivalent compressive toughness.

\begin{tabular}{|c|c|c|c|c|c|c|}
\hline \multirow[t]{2}{*}{ Specimen no. } & $\Omega_{1.00}$ & $\Omega_{0.85}$ & $\Omega_{0.30}$ & $w_{c}^{1.00}$ & $w_{c}^{0.85}$ & $w_{c}^{0.30}$ \\
\hline & \multicolumn{3}{|c|}{$\times 10^{5}(\mathrm{~N} \cdot \mathrm{mm})$} & \multicolumn{3}{|c|}{$\left(\times 10^{-2}\right)$} \\
\hline $\mathrm{A} 1$ & 2.24 & 3.10 & 3.77 & 3.325 & 4.594 & 5.582 \\
\hline $\mathrm{A} 2$ & 2.87 & 3.21 & 4.93 & 4.252 & 4.759 & 7.310 \\
\hline A3 & 3.20 & 4.02 & 5.59 & 4.742 & 5.950 & 8.281 \\
\hline A4 & 4.35 & 5.12 & 7.44 & 6.438 & 7.579 & 11.019 \\
\hline A5 & 3.79 & 4.59 & 6.58 & 5.612 & 6.801 & 9.755 \\
\hline A6 & 4.08 & 5.69 & 10.37 & 6.040 & 8.433 & 15.360 \\
\hline A7 & 4.26 & 5.46 & 7.47 & 6.313 & 8.086 & 11.061 \\
\hline A8 & 3.99 & 4.83 & 6.87 & 5.919 & 7.152 & 10.178 \\
\hline A9 & 4.05 & 5.12 & 10.87 & 6.001 & 7.593 & 16.108 \\
\hline A10 & 4.21 & 5.00 & 8.06 & 6.243 & 7.400 & 11.936 \\
\hline A11 & 3.46 & 4.23 & 5.93 & 5.126 & 6.267 & 8.785 \\
\hline A12 & 3.54 & 4.59 & 7.78 & 5.242 & 6.802 & 11.532 \\
\hline A13 & 3.96 & 4.46 & 6.88 & 5.864 & 6.604 & 10.190 \\
\hline A14 & 4.44 & 5.42 & 8.49 & 6.580 & 8.036 & 12.587 \\
\hline A15 & 4.46 & 6.74 & 13.16 & 6.604 & 9.982 & 19.491 \\
\hline A16 & 4.46 & 6.01 & 10.15 & 6.613 & 8.908 & 15.031 \\
\hline $\mathrm{A} 17$ & 4.79 & 5.91 & 10.43 & 7.103 & 8.760 & 15.455 \\
\hline A18 & 4.82 & 7.22 & 15.53 & 7.142 & 10.693 & 23.002 \\
\hline A19 & 5.14 & 6.80 & 13.07 & 7.612 & 10.079 & 19.363 \\
\hline
\end{tabular}



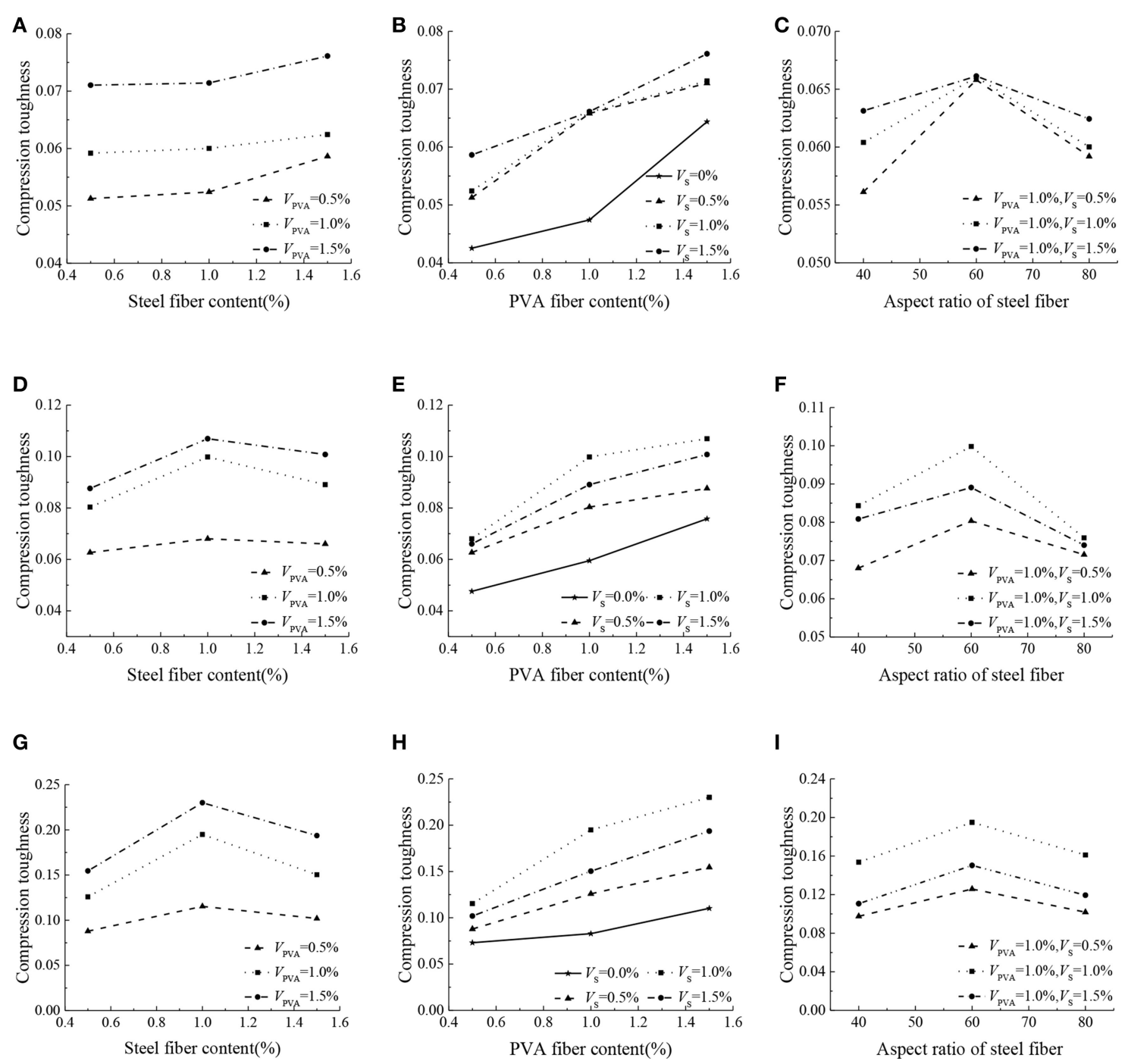

FIGURE 6 | The influence of various parameters for the compressive toughness. (A) Influence of steel fiber content on $\Omega_{1.00}$. (B) Influence of PVA fiber content on $\Omega_{1.00}$. (C) Influence of aspect ratio of steel fiber on $\Omega_{1.00}$. (D) Influence of steel fiber content on $\Omega_{0.85}$. (E) Influence of PVA fiber content on $\Omega_{0.85}$. (F) Influence of aspect ratio of steel fiber on $\Omega_{0.85}$. (G) Influence of steel fiber content on $\Omega_{0.30}$. (H) Influence of PVA fiber content on $\Omega_{0.30}$. (I) Influence of aspect ratio of steel fiber on $\Omega_{0.30}$.

fiber content remains constant. When the volume fraction of steel fiber is $1 \%$, the compressive toughness index values are maximum. The negative fiber hybridization effect occurs when the volume fraction of steel fiber increases from 1.0 to $1.5 \%$.

In HyFRCC, the total number of steel fibers decreases with the increase of the aspect ratio of steel fiber when the steel fiber content remains constant. Therefore, the number of steel fibers that bridging cracks will decrease. As shown in Figures 6 C,F,I, with the increase of the aspect ratio of steel fiber, the compressive toughness of the HyFRCC specimens increases first and then decreases. When the aspect ratio of steel fiber is 60 , the compressive toughness index values are maximum.

\section{CONCLUSION}

The fiber content and geometrical characteristics are the main factors affecting the axial compressive strength of HyFRCC material. The addition of fibers leads to the reduction of the axial compressive strength of the matrix material. The axial compressive strength of HyFRCC material increases with the increase of the PVA fiber and steel fiber content. The relationship between the axial compressive strength of HyFRCC and the fiber characteristic value is established according to the test results, which provides a reference for engineering application of HyFRCC.

The uniaxial compressive peak strain of HyFRCC significantly increases with the addition of fiber. The peak strain of ECC is 
$55 \sim 105 \%$ higher than that of the non-fibrous cementitious composites. The peak strain of HyFRCC increases remarkably with the addition of steel fiber. And the peak strain of HyFRCC increases by $104 \sim 167 \%$ when the volume fraction of steel fiber is $0.5 \sim 1.5 \%$. The deformation capability is significantly improved before reaching peak load.

Comparing with the non-fibrous cementitious composites, $W_{\mathrm{c}}^{0.85}$ and $W_{\mathrm{c}}^{0.30}$ values of ECC only increases by 24.92 and $58.90 \%$ on average, respectively. The crack control capability of HyFRCC is improved with the addition of steel fiber. The ductility and compressive toughness after peak load is also improved significantly. $W_{\mathrm{c}}^{0.85}$ and $W_{\mathrm{c}}^{0.30}$ values of HyFRCC increase by 76.46 and $150.61 \%$ on average, respectively.

The PVA fiber content, steel fiber content and aspect ratio of steel fiber have a significant effect on the compressive toughness of HyFRCC material. The compressive toughness of the HyFRCC is optimized when the PVA fiber content is $1.0 \%$, the steel fiber content is $1.5 \%$, and the aspect ratio of steel fiber is 60 .

\section{REFERENCES}

Ali, M. A., Soliman, A. M., and Nehdi, M. L. (2017). Hybrid-fiber reinforced engineered cementitious composite under tensile and impact loading. Mater. Design 117, 139-149. doi: 10.1016/j.matdes.2016.12.047

Cai, X., and Xu, S. (2011). Uniaxial compressive properties of ultra high toughness cementitious composite. J. Wuhan Univ. Tech. Mater. Sci. Ed. 26, 762-769. doi: 10.1007/s11595-011-0307-0

Deng, M., Liu, H., Qin, M., and Liang., X. (2015). Experimental research on compressive toughness of the high ductile fiber reinforced concrete. J. Xian Univ. Arch. Tech. 47, 660-665. doi: 10.15986/j.1006-7930.2015.05.009

Fan, J., Shi, Z., Gou, S., Nie, X., and Zhang, J. (2017). Experimental research on negative bending behavior of steel -ECC composite beams. China Civil Eng. J. 50, 64-72. doi: 10.15951/j.tmgcxb.2017.04.008

Kasai, K., Fu, Y., and Watanabe, A. (1998). Passive control systems for seismic damage mitigation. J. Struc. Eng. 124, 501-512. doi: 10.1061/(ASCE)0733-9445(1998)124:5(501)

Kawamata, A., Mihashi, H., and Fukuyama, H. (2003). Properties of hybrid fiber reinforced cement-based composites. J. Adv. Concr. Technol. 1, 283-290. doi: $10.3151 /$ jact.1.283

Lawler, J. S., Zampini, D., and Shah, S. P. (2005). Microfiber and macro-fiber hybrid fiber reinforced concrete. ASCE J. Mater. Civil Eng. 17, 595-604. doi: 10.1061/(ASCE)0899-1561(2005)17:5(595)

Li, V. C. (1993). From micromechanics to structural engineering - the design of cementitous composites for civil engineering applications. JSCE J. Struc. Mech. Earthq. Eng. 471, 1-12. doi: 10.2208/jscej.1993.471_1

Li, V. C., and Leung, C. K. Y. (1992). Steady-state and multiple cracking of short random fiber composites. J. Eng. Mech. 118, 2246-2264. doi: 10.1061/(asce)0733-9399(1992)118:11(2246)

Liu, S., Huang, C., Wang, Q., and Zhao, G. (2005). Experimental investigation of uniaxial compressive characteristics of steel fiber improved high-strength concrete. Indust. Constr. 35, 78-80. doi: 10.13204/j.gyjz2005.11.023

Maalej, M., Quek, S. T., and Zhang, J. (2005). Behaviour of hybridfiber engineered cementitious composites subjected to dynamic tensile loading and projectile impact. ASCE J. Mater. Civil Eng. 17, 143-152. doi: 10.1061/(ASCE)0899-1561(2005)17:2(143)

Qian, S., Lepech, M. D., Kim, Y. Y., and Li, V. C. (2009). Introduction of transition zone design for bridge deck link slabs using ductile concrete. ACI Struc. J. 106, 96-105. doi: 10.14359/56288

Soe, K. T., Zhang, Y. X., and Zhang, L. C. (2013). Material properties of a new hybrid fibre-reinforced engineered cementitious composite. Construc. Build. Mater. 43, 399-407. doi: 10.1016/j.conbuildmat.20 13.02 .021
The compressive toughness, deformation and energy dissipation capacity of PVA-steel HyFRCC can be significantly improved. It is indicated that PVA-steel HyFRCC can be used for vibration isolation and mitigation of structures to improve the seismic performance of structures (Kasai et al., 1998; Xu et al., 2017, 2019).

\section{DATA AVAILABILITY}

The datasets generated for this study are available on request to the corresponding author.

\section{AUTHOR CONTRIBUTIONS}

WL and $\mathrm{JH}$ designed and prepared the specimens and conducted the test. Further analysis was performed by WL under the supervision of JH. All the authors collaborated on the writing of the manuscript.

Wang, S., and Li, V. C. (2006). High-early-strength engineered cementitious composites. ACI Mater. J. 103, 3-12. doi: 10.14359/15260

Wang, Z., Zhang, J., Wang, J., and Shi, Z. (2015). Tensile performance of polyvinyl alcohol-steel hybrid fiber reinforced cementitious composite with impact of water to binder ratio. J. Comp. Mater. 49, 2169-2186. doi: $10.1177 / 0021998314542450$

Wang, Z., Zuo, J., Zhang, J., Feng, L., and Jiang, G. (2018). Mechanical properties of hybrid fiber reinforced cementitious composites under uniaxial compression. J. Build. Mater. 21, 639-644. doi: 10.3969/j.issn.1007-9629.2018.04.018

$\mathrm{Xu}$, S., Cai, X., and Zhang, Y. (2009). Experimental measurement and analysis of the axial compressive stress-strain curve of ultra high toughness cementitious composites. China Civil Eng. J. 42, 79-85. doi: 10.15951/j.tmgcxb.2009.11.009

Xu, Z., Huang, X., Xu, F., and Yuan, J. (2019). Parameters optimization of vibration isolation and mitigation system for precision platforms using nondominated sorting genetic algorithm. Mech. Syst. Signal Process. 128, 191-201. doi: 10.1016/j.ymssp.2019.03.031

Xu, Z., Suo, S., Zhu, J., and Guo, Y. (2017). Performance tests and modeling on high damping magnetorheological elastomers based on bromobutyl rubber. J. Intel. Mater. Syst. Struc. 29, 1025-1037. doi: 10.1177/1045389X17730909

Zhang, J., Gong, C., Guo, Z., and Zhang, M. (2009). Engineered cementitious composite with characteristic of low drying shrinkage. Cem. Concrete Res. 39, 303-312. doi: 10.1016/j.cemconres.2008.11.012

Zhang, J., Maalej, M., and Quek, S. (2007). Performance of hybrid-fiber ECC blast/shelter panels subjected to drop weight impact. ASCE J. Mater. Civil Eng. 19, 855-863. doi: 10.1061/(ASCE)0899-1561(2007)19:10(855)

Zhou, J., Pan, J., and Leung, C. K. Y. (2015). Mechanical behavior of fiberreinforced engineered cementitious composites in uniaxial compression. J. Mater. Civil Eng. 27:04014111. doi: 10.1061/(ASCE)MT.1943-5533.0001034

Zhou, T., Tian, P., Deng, M., Zhao, X., Zhang, H., and Liang, Z. (2018). Research on shaking table test of cavity-wall building strengthened with engineered cementitious composite. J. Build. Struct. 39, 147-152. doi: 10.14006/j.jzjgxb.2018.12.017

Conflict of Interest Statement: The authors declare that the research was conducted in the absence of any commercial or financial relationships that could be construed as a potential conflict of interest.

Copyright (c) 2019 Liu and Han. This is an open-access article distributed under the terms of the Creative Commons Attribution License (CC BY). The use, distribution or reproduction in other forums is permitted, provided the original author(s) and the copyright owner(s) are credited and that the original publication in this journal is cited, in accordance with accepted academic practice. No use, distribution or reproduction is permitted which does not comply with these terms. 